\title{
Indicação Geográfica e educação não-formal em comunidades tradicionais: uma proposta de oficinas colaborativas
}

\author{
Indicación Geográfica y educación no formal en comunidades \\ tradicionales: una propuesta de talleres colaborativos
}

\section{Geographic Indication and non-formal education in traditional communities: a proposal for collaborative workshops}

\author{
Janaina Cardoso Mello \\ janainamello@uol.com.br \\ Universidade Federal de Sergipe, UFS, Aracaju, SE
}

\begin{abstract}
Resumo: O artigo apresenta a proposta da realização oficinas de Educação não-formal para instrumentalização das comunidades no conhecimento das Indicação Geográficas (IGs), tendo como parâmetros: o levantamento de suas potencialidades (produtos); a viabilidade real de comercialização, tendo em vista o regulamento de uso requerido pelo Instituto Nacional de Propriedade Industrial e o empoderamento dos agentes sociais através do reforço de sua autonomia e ação coletiva. A metodologia para a instrumentalização das IGs como apoio ao desenvolvimento da Economia Criativa local, em seu planejamento, divide-se em três etapas com seis encontros: 1) Pesquisa, Teoria e Método para Ministrantes, através da coleta de dados em bases de pesquisa e gestão pública; 2) Sensibilização da Comunidade e Oficinas, com atividades dinâmicas envolvendo diagramas, nuvem de palavras e Mandalas e 3) Validação dos resultados, elaboração de documentação institucional e demanda da gestão pública para o registro e apoio à melhoria da qualidade de vida dos produtores.
\end{abstract}

Palavras-chave: Economia Criativa, Associações, Certificação, Empoderamento comunitário.

Resumen: El artículo presenta la propuesta de llevar a cabo talleres de educación no formal para la instrumentalización de las comunidades en el conocimiento de la Indicación Geográfica (IG), teniendo como parámetros: la encuesta de sus potencialidades (productos y servicios); La viabilidad real de la comercialización, en vista de la regulación de uso requerida por el Instituto Nacional de la Propiedad Industrial (INPI) y el empoderamiento de los agentes sociales mediante el refuerzo de su autonomía, tradición cultural y acción colectiva. El Metodología al instrumentalización de las IGs como apoyo al desarrollo de la economía creativa local, en su planificación, se divide en tres etapas con seis encuentros: 1) Investigación, teoría y método para los ministros, a través de la recopilación de datos en bases de investigación y gestiónpública;2) sensibilización comunitaria y talleres, con actividades dinámicas que implican diagramas, nube de palabras y Mandalas y3) Validación de los resultados, elaboración de documentación institucional y demanda de gestión pública para el registro y apoyo para mejorar la calidad de vida de los productores.

Palabras clave: Economía Creativa, Asociaciones, Certificación, Empoderamiento comunitario. 


\begin{abstract}
This paper presents the proposal of carrying out non-formal education workshops for exploitation of communities in knowledge of the Geographical Indication (IGs), having as parameters: raising its potential (products); the actual feasibility of commercialization with a view to the regulation of use required by the National Institute of Industrial Property and the empowerment of the social agents through the strengthening of your autonomy and collective action. The Methodology to the instrumentalization of IGs as support development of the local creative economy, in its planning, is divided into three stages with six encounters: 1) Research, theory, and method for ministers, through data collection in research bases and public management; 2) community awareness and workshops, with dynamic activities involving diagrams, word cloud, and Mandalas and 3) Validation of the results, elaboration of institutional documentation and demand of public management for the registration and support to improve the quality of life of the producers.
\end{abstract}

Keywords: Creative Economy, Associations, Certification, Community Empowerment.

\title{
INTRODUÇÃO
}

Qual a marca do café que lhe acorda o ânimo todas as manhãs? Ele possui certificação de origem? E aquele doce português que faz o sorriso emergir depois de saciada a fome do horário do almoço? Tem selo de qualidade?

Nos países europeus uma grande parte dos habitantes possui o costume de frenquentar feiras de produtos agrícolas-artesanais para adquirir produtos com certificação de qualidade conferido pelos organismos reguladores da União Europeia (EU), mesmo pagando um valor mais elevado. Só em Portugal existem mais de 115 produtos com proteção de origem e qualidade agroalimentar em várias regiões do país (ZANANDREA et al., 2017, p.544).

No Brasil a relação da população com as Indicações Geográficas (IGs) concedidas pelo Instituto Nacional de Propriedade Industrial (INPI) ainda envolve muito desconhecimento, e mais ainda nas comunidades tradicionais, com equivocadas apropriações de sentido e ausência do apoio das gestões públicas, ignorando-se muitas vezes que

[...] as Indicações Geográficas (IG) representam um importante papel nas políticas públicas de desenvolvimento, sobretudo regional. Ao inserir globalmente estes produtos tipicamente locais (nacionais) protegidos por IG, além de conquistar espaço nos mercados, se fomenta a geração de empregos e renda local (fixando a produção na região de origem) e promove a organização dos produtores, visando a qualidade dos produtos e serviços (SOUSA et al., 2019, p.380).

Conceitualmente, de acordo com o Serviço Brasileiro de Apoio às Micro e Pequenas Empresas (SEBRAE) e o Instituto Nacional de Produção Industrial (INPI), a Indicação Geográfica (IG) consiste no registro do nome geográfico de um país, cidade ou região, reconhecido pela qualidade ou tradição de determinado produto ou serviço", dividindo-se em duas tipologias: 
Indicação de procedência (IP) - Nome geográfico que se tenha tornado conhecido como centro de extração, produção ou fabricação de determinado produto ou de prestação de determinado serviço.

Denominação de origem (DO) - Nome geográfico que designe produto ou serviço cujas qualidades ou características se devam exclusiva ou essencialmente ao meio geográfico, incluídos fatores naturais e humanos (SEBRAE; INPI, 2017).

O registro de IG requer nome e delimitação da área e produto, anexando comprovantes da legitimidade do requerente, delimitação da área geográfica e descrição do produto ou serviço, bem como representação gráfica ou figurativa da Indicação Geográfica. Também é necessário comprovar que os produtores ou prestadores de serviços exercem a atividade econômica que buscam proteger; com uma estrutura de controle sobre o uso exclusivo da Indicação Geográfica de seu produto ou serviço (INPI, 2019a).

Inicialmente o processo parece ser direcionado as empresas, todavia, ele está aberto as associações e cooperativas comunitárias de povoados e regiões interioranas que têm descoberto esse instrumento de certificação de sua produção agropecuária, artesanal, tecnológica ou geológica para a valorização de seus saberes tradicionais, reconhecimento de sua propriedade intelectual e aumento de rentabilidade na negociação. Um exemplo encontra-se no município de Pinto Bandeira (RS) com vinícolas certificadas com IG, destaque na produção de pêssegos e potencialidade para a realização de turismo agrícola e/ ou enoturismo, assim

A Associação dos Produtores de Vinhos de Pinto Bandeira (Asprovinho) foi criada em 29 de junho de 2001 e, segundo seus estatutos, tem com o objetivo proteger a natureza, a cultura local, os produtores de vinho e, sobretudo, preservar a qualidade e afirmar a identidade dos vinhos e espumantes produzidos no local. Os vinhos produzidos no território que detém o selo de IP são denominados "Vinhos Pinto Bandeira". O controle de qualidade é realizado pela Asprovinho, a qual contempla desde o cadastramento dos vinhedos e vinícolas, análises químicas, degustação e selo de controle (MAIORKI; DALLABRIDA, 2015, p.20).

Entretanto, em pequenos povoados - com adultos com escolaridade limitada - as etapas de desenvolvimento desse processo poderão revelar uma difícil compreensão na ausência do acompanhamento por outras instâncias como o SEBRAE, Organizações Não Governamentais (ONGs), prefeituras, governos estaduais e fundamentalmente as universidades públicas.

Por isso, este artigo apresenta a proposta da realização de oficinas de Educação não-formal para instrumentalização das comunidades no conhecimento das IGs, tendo como parâmetros: o levantamento de suas potencialidades (produtos); a viabilidade da comercialização com obtenção de lucro, tendo em vista o regulamento de uso requerido pelo INPI e o empoderamento dos atores sociais através do reforço de sua autonomia e ação coletiva para autogestão econômica.

Para isso, o método adotado nas oficinas segue os princípios da Educação Patrimonial relacionando observação, experimentação (ou 'aprender fazendo'), diálogo, análise e registro 
(HORTA, 2019, p.1-2). Sob esse aspecto, após a realização dos contatos necessários para que a comunidade crie uma relação de confiabilidade com os pesquisadores/ representantes da gestão pública, os ministrantes das oficinas devem empregar metodologias dinâmicas para a interação com os agentes sociais produtores.

\section{AS IGS E O INPI: ADENTRANDO O CONHECIMENTO DO TEMA}

O site do INPI lista as Indicações Geográficas na modalidade de Indicação de Procedência (IP), com 42 produtos brasileiros registrados - 34 IP e 8 DO: (1) o café - Alta Mogiana, (2) vinhos e espumantes - Altos Montes, (3) o mármore - Cachoeiro de Itapemirim, (4) o queijo - Canastra, (5) a renda renascença - Cariri Paraibano, (6) a renda de agulha em lacê/ renda irlandesa - Divina Pastora, (7) os calçados - Franca, (8) as panelas de barro - Goiabeiras, (9) o cacau em amêndoas - Linhares, (10) os vinhos - Monte Belo, (11) o melão - Mossoró, (12) o café verde em grão e industrializado torrado em grão e/ ou moído - Norte Pioneiro do Paraná, (13) a carne bovina e seus derivados - Pampa Gaúcho da Campanha Meridional, (14) os têxteis em algodão colorido - Paraíba, (15) os aguardentes, tipo cachaça e aguardente composta azulada - Paraty, (16) as opalas preciosas de Pedro II e jóias artesanais de opala de Pedro II - Pedro II, (17) os doces finos tradicionais e de confeitaria - Pelotas, (18) os vinhos tinto, branco e espumantes - Pinto Bandeira, (19) os serviços de tecnologia da informação - TI - Porto Digital, (20) o café - Região da Serra da Mantiqueira de Minas Gerais, (21) a aguardente de cana tipo cachaça - Região de Salinas, (22) o café - Região do Cerrado Mineiro, (23) o artesanato em Capim Dourado - Região do Jalapão do Estado do Tocantins, (24) as peças artesanais em estanho - São João Del Rei, (25) os biscoitos - São Tiago, (26) o queijo - Serro, (27) o couro acabado - Vale dos Sinos, (28) as uvas de mesa e manga - Vale do Submédio São Francisco, (29 e 30) os vinhos tinto, branco e espumante - Vale dos Vinhedos, (31) o vinho de uva Goethe - Vales da Uva Goethe, (32) o arroz do Litoral Norte Gaúcho, (33) o café da Serra da Mantiqueira, (34) camarões da Costa Negra, (35 e 36) os gnaisses do Rio de Janeiro, (37) a própolis dos manguezais de Alagoas, (38) o café do Cerrado mineiro; (39) cajuína do Piauí, (40) peixes ornamentais do Rio Negro, (41) a cachaça da microrregião de Abaíra e (42) mel do Pantanal. Giesbrecht et al. (2014a) relacionam a distribuição espacial da maior parte das Indicações de Procedência (IP) na Figura 1. 
Figura 1. Distribuição das Indicações Geográficas brasileiras, modalidade IP.

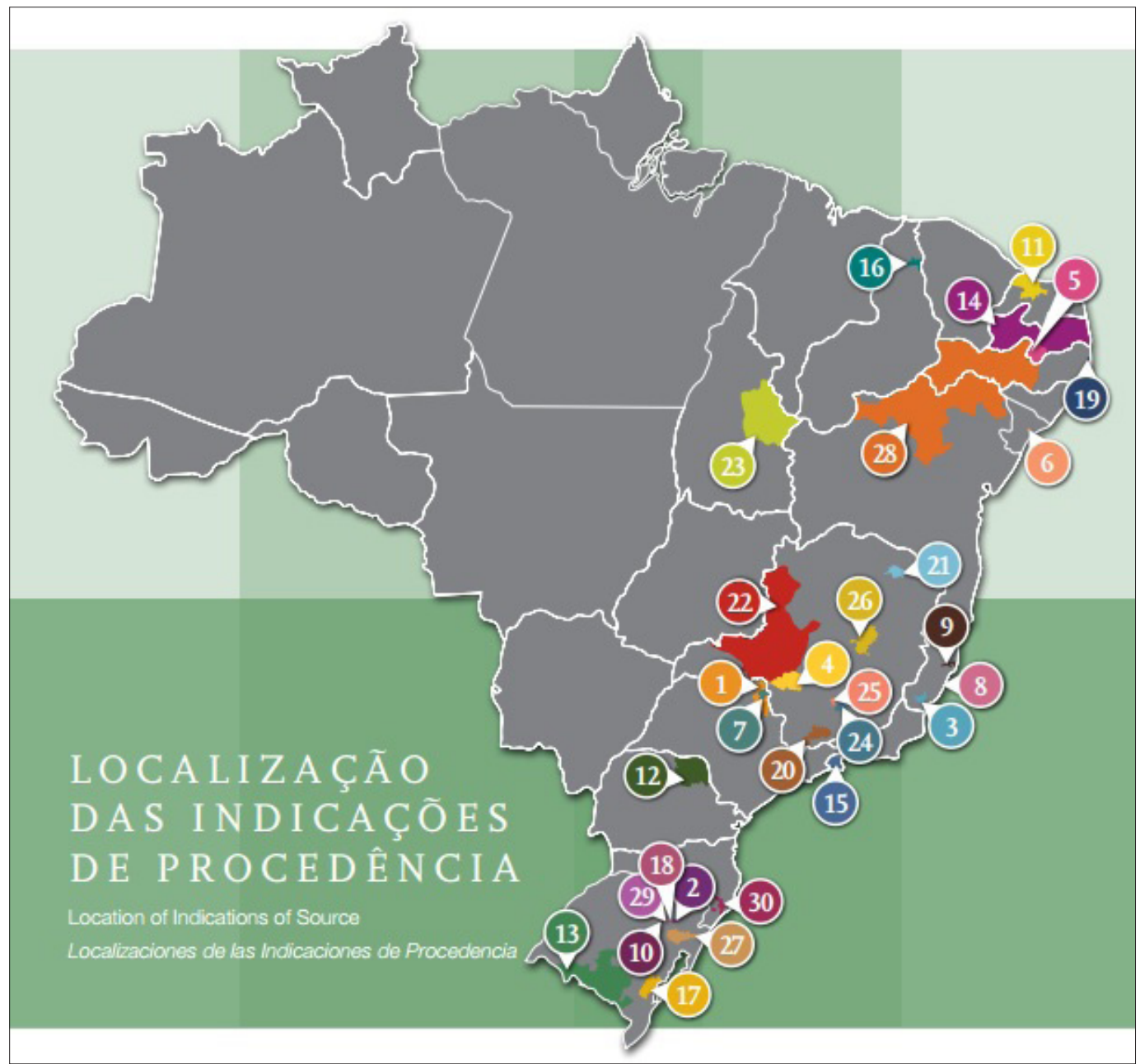

Fonte: Giesbrecht et al., 2014a.

O mapeamento permite identificar um grande contingente de registros na parte leste, do Norte ao Sul, sendo quase inexistente na topografia oeste principalmente na região amazônica e no Centro-Oeste brasileiro. Há uma predominância de registros no sudeste (treze IGs) e sul (nove IGs) totalizando vinte e dois registros. O Nordeste aparece com sete registros e há apenas um registro para o Norte, no Tocantins ${ }^{1}$.

Foram também mapeadas oito IGs na modalidade Denominação de Origem (Fig. 2): (1) Camarões - Costa Negra; (2) Arroz - Litoral Norte Gaúcho; (3) Própolis vermelha e extrato de própolis vermelha - Manguezais de Alagoas; (4) Café verde em grão e café industrializado torrado em grão ou moído - Região do Cerrado Mineiro; (5) Gnaisse fitado milonítico de coloração branca e pontos vermelhos - Região Pedra Carijó Rio de Janeiro; (6) Gnaisse fitado milonítico de coloração branca e pontos vermelhos - Região Pedra Cinza Rio de Janeiro; (7) Gnaisse fitado milonítico de coloração branca e pontos vermelhos - Região

1 Entre 2014 e 2015 houve mais quatro registros de IP, nos estados do Piauí, Amazonas, Mato Grosso e Bahia, passando a nove registros na região Nordeste e três na região Norte. 
Pedra Madeira Rio de Janeiro; (8) Vinhos: tinto, branco e espumante - Vale dos Vinhedos (GIESBRECHT et al., 2014a, p.210).

Nesse caso mantêm-se a predominância do registro de IGs para a região Sudeste (quatro) e Sul (duas) totalizando seis DOs, possuindo o Nordeste duas IGs e nenhum registro para as regiões Norte e Centro-Oeste do Brasil.

Figura 2. Distribuição das Indicações Geográficas, modalidade DO

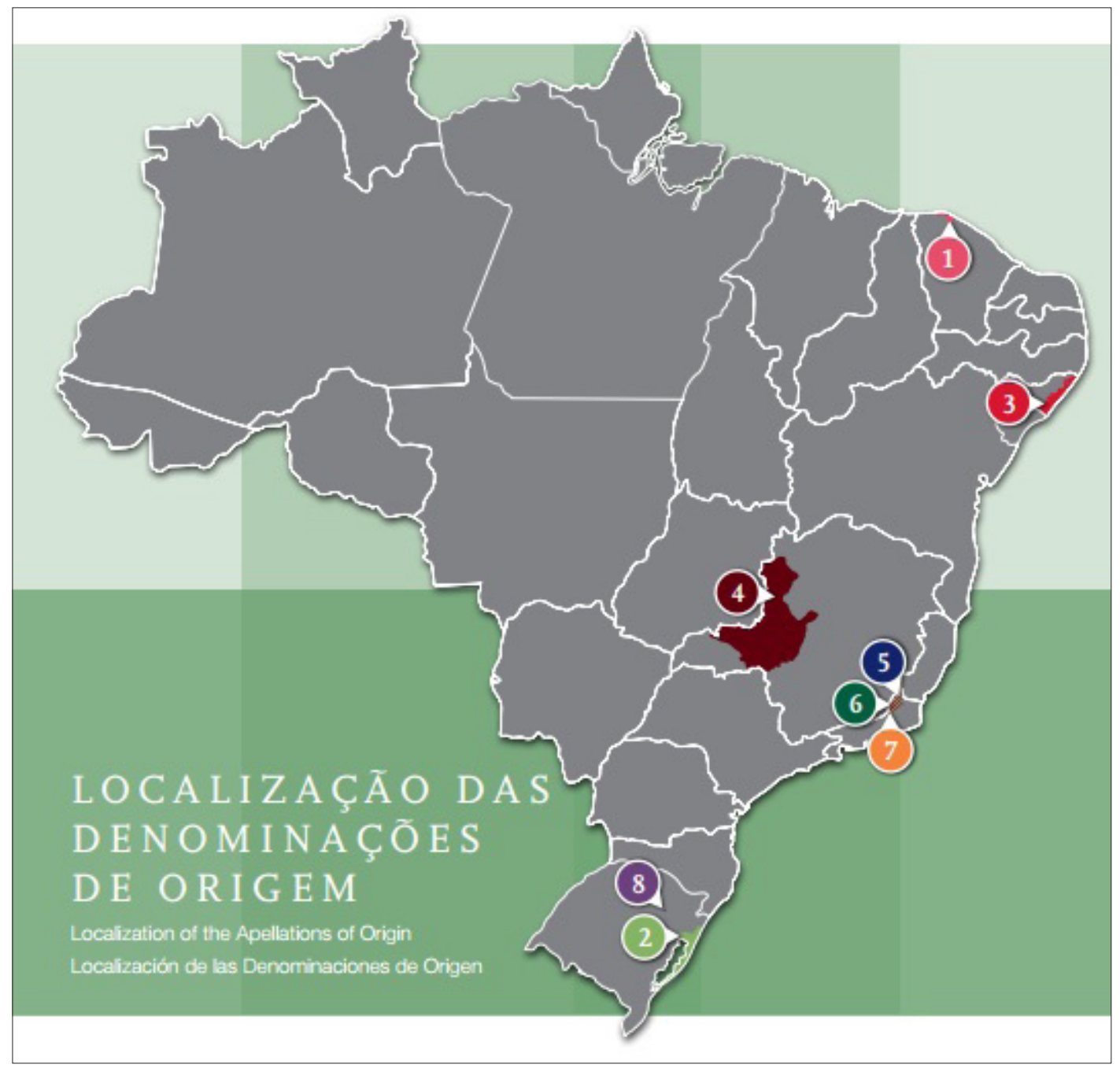

Fonte: Giesbrecht et al., 2014a.

Percebendo a necessidade de uma caracterização mais cultural, SEBRAE e INPI, em 2014, lançaram uma publicação específica para os produtos artesanais contendo sete IGs registradas (Fig.3), estando a maioria localizada na região Nordeste (quatro), com apenas uma no Norte e duas na região Sudeste. Não foram identificadas incidências nas regiões Centro-Oeste e Sul. 
Figura 3. Mapa das Indicações Geográficas relativas a Artesanato.

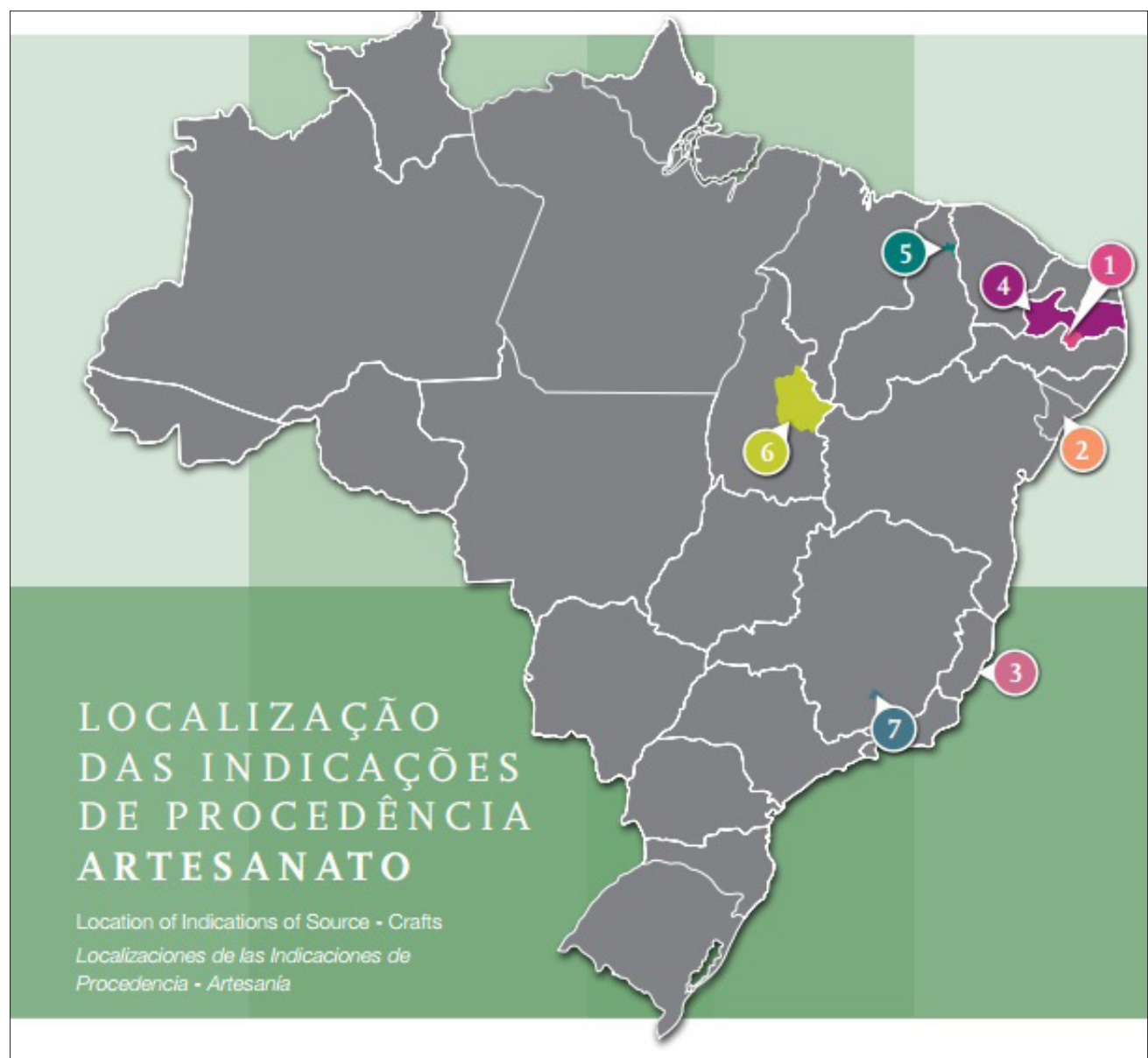

Fonte: Giesbrecht et al., 2014b.

O mapa apresenta sete IGs de artesanato: (1) a renda renascença - Cariri Paraibano, (2) a renda de agulha em lacê/ renda irlandesa - Divina Pastora, (3) as panelas de barro Goiabeiras, (4) os têxteis em algodão colorido - Paraíba, (5) as opalas preciosas de Pedro II e jóias artesanais de opala de Pedro II - Pedro II, (6) o artesanato em Capim Dourado - Região do Jalapão do Estado do Tocantins, (7) as peças artesanais em estanho - São João Del Rei (GIESBRECHT et al., 2014b).

Um quadro das IGs de IP concedidas até março de 2017 junto ao INPI revela mais seis registros, de quatro regiões brasileiras:

Tabela 1 - IGs de IP registrados entre 2015 e 2016.

\begin{tabular}{c|c|c|c}
\hline PRODUTO & REGISTRO DA IG & ANO & LOCAL \\
\hline Linguiça - Maracaju & BR402014000007-7 & 2015 & Mato Grosso do Sul \\
\hline Açafrão - Mara Rosa & BR402013000006-6 & 2016 & Goiás \\
\hline Bordado Filé - Região das Lagoas de Mundaú-Manguaba & BR402014000012-3 & 2016 & Alagoas \\
\hline Goiaba - Carlópolis & BR402015000008-8 & 2016 & Paraná \\
\hline Café Verde e Café Torrado e Moído - Região de Pinhal & BR402014000001-8 & 2016 & São Paulo \\
\hline Inhame - Região São Bento de Urânia & BR402014000004-2 & 2016 & Espírito Santo \\
\hline
\end{tabular}

Fonte: INPI, 20 mar. 2017. 
De 2014 a 2016 houve uma significativa mudança no quadro geográfico de registro de IGs no país, inserindo a região Centro-Oeste com Goiás e Mato Grosso do Sul no mapa das certificações, além de reconhecer um bordado de Alagoas. O total de IGs na modalidade IP concedidas junto ao INPI em março de 2017 perfaz 41 registros nacionais. Enquanto a quantificação das IGs reconhecidas como DO constitui ao todo dez registros nacionais e oito internacionais (INPI, 2017).

Mas o que tem levado grupos diversificados, imersos na ambiência do mercado, a solicitar as IGs de seus produtos junto ao INPI? Há uma questão de antecedentes, desse modo, afirma-se que a noção da IG, remontando sua importância geográfica, histórica e atual,

[...] surgiu de forma gradativa, quando produtores e consumidores passaram a perceber os sabores ou qualidades peculiares de alguns produtos que provinham de determinados locais. Ou seja, qualidades - nem melhores nem piores, mas típicas, diferenciadas - jamais encontradas em produtos equivalentes feitos em outro local (PIMENTEL, 2014, p.33).

O INPI foi criado em 1970, configurando-se como uma autarquia federal vinculada ao Ministério da Indústria, Comércio Exterior e Serviços, tendo por atribuições o aperfeiçoamento, a disseminação e a gestão do sistema brasileiro de concessão e garantia de direitos de propriedade intelectual para a indústria (INPI, 2016). Ao assegurar os direitos de propriedade intelectual de diversas modalidades, o INPI enfatiza que "na economia do conhecimento, estes direitos se transformam em diferenciais competitivos, estimulando o surgimento constante de novas identidades e soluções técnicas" (INPI, 2016, on line).

Em 2012, a imprensa nacional noticiou em seus Cadernos de Economia o aumento de $20 \%$ para $40 \%$ na comercialização da Cajuína do Piauí no mercado brasileiro. Somente em 2011 foram vendidas 1,5 milhões de garrafas do produto (MARTINS, 2017). A Central de Cooperativas de Cajucultores do Piauí (COCAJUPI), situada no município de Picos, região centro sul do Piauí, tem trabalhado as atividades de produção, distribuição e consumo de alimentos e da matéria prima da castanha de caju como um empreendedorismo solidário onde os cooperadores são donos de todo complexo que abrange diversas etapas da cadeia produtiva (CARVALHO, 2017).

Ao final de 2014, após a certificação da IG, houve um movimento financeiro de mais de 2 milhões de reais na comercialização da Cajuína associada à Cooperativa dos Cajucultores do Estado do Piauí - CAJUESPI (PORTAL AZ, 2017). Resultados como estes instigaram o interesse dos produtores na busca pelo selo de qualidade para seus produtos, além de impedir que produtores de outras localidades copiem suas criações e revendam por preços menores, uma vez que a IG também confere a propriedade intelectual dos produtos.

\section{COMUNIDADES CRIATIVAS E CONHECIMENTO COMO EMPODERAMENTO}

Richard Florida (2002) compreende a 'cidade criativa', como um espaço capaz de agregar os valores e desejos da 'nova classe criativa', formada pelo talento e conhecimento 
de cientistas, artistas, empresários, capitalistas de risco, além de outras pessoas criativas, que têm enorme impacto na determinação de como é organizado o espaço de trabalho e, portanto, se as companhias vão prosperar, e se a cidade vai se desenvolver ou não. Ou seja, comunidades criativas podem reverberar seu talento, imaginação e iniciativa para que a cidade se torne criativa, ampliando seu potencial de atuação cidadã, suas redes de solidariedade e sustentabilidade socioeconômica e ambiental.

A renda renascença do Cariri (PB) revelou o potencial criativo das artesãs na transformação da economia local através de seu modo-de-fazer. Surgida entre os séculos XV e XVI, sendo símbolo artesanal italiano, encantou também aos franceses da realeza à burguesia no século XVIII. No Brasil, chegou ao Nordeste no século XIX, através das freiras francesas do Convento Santa Teresa. Mas somente na década de 1930 o conhecimento foi apropriado pelas mulheres mais humildes (GIESBRECHT et al., 2014a) e a partir de então tornou-se um importante fonte de subsistência. O produto foi contemplado com IG (IP) em 2013, conferindo maior visibilidade, demanda por aquisição e valor monetário na negociação da renda produzida naquela região.

Outro exemplo disso está na região do Jalapão, em Tocantins, cujo saber fazer de seu artesanato tradicional com influências indígenas e quilombolas transformou o capim dourado e a seda do buriti em peças trançadas com delicadeza e arte conformadas em bolsas, bijuterias, vasos, etc. (GIESBRECHT et al., 2014a). O Artesanato em Capim Dourado obteve a IG (IP) em 2011 e "cada peça que sai da comunidade está adornada com as histórias e sonhos de mulheres que desejam um futuro ainda melhor" (OLIVEIRA, 2016, on line).

Ainda de 2011 é a IG (IP) das panelas de barro da região de Goiabeiras (ES) cuja criatividade das paneleiras - uma herança cultural indígena e africana -, com sua produção utilitária ligada à gastronomia, tornou-se indissociável da apresentação dos pratos de moquecas e outros derivados de frutos do mar, configurando-se em um requisito utensílio da cozinha brasileira e mesmo internacional. (GIESBRECHT et al., 2014a). Observou-se que mesmo após a intensa urbanização, o local mantém a tradição de fazer do barro panelas. Daí as reconhecidas paneleiras, que aprenderam a técnica geracional com suas mães, avós e bisavós (ARTESOL, 2019).

Tais produtos com forte matriz cultural, com significativa relação identitária entre a comunidade e sua ancestralidade, evocam também um poderoso matriarcado na geração de renda e sustento familiar.

No livro Cidades Criativas - perspectivas, organizado por Reis e Kageyama (2011), na p. 11 consta que

Inicialmente, o conceito de 'cidade criativa' foi considerado o de um lugar onde os artistas desempenhavam um papel central e onde a imaginação definia os traços e o espírito da cidade. Ao longo do tempo, as indústrias criativas, do design à música, das artes do espetáculo às visuais, ocuparam o centro da cena dos debates, por seu papel como eixo econômico, criador de identidade urbana ou fator de geração de turismo e imagem. Em seguida, a presença de uma grande "classe criativa", que inclui as acima citadas, assim como a comunidade de pesquisa e os nômades do conhecimento, foi vista como um indicador básico de cidade criativa. 
O que se percebe é a ênfase na ideia de criatividade, esteja ela vinculada ou não à tecnologia transforma a visão sobre a cidade, tornando-a mais subjetiva, mais palatável, mais plural em sua significação para seus habitantes em sua rotina de sobrevivência.

Ashton (2015, p.292) trata das cidades criativas como ambientes dinâmicos e em constante adaptação às necessidades econômicas e de qualidade de vida urbana, fundadas na cultura da criatividade. Ashton busca a origem do termo 'cidades criativas' no conceito de 'economia criativa', emergido na Austrália em 1994, articulando o trabalho criativo ao desenvolvimento econômico favorecido pelas tecnologias como impulsionadoras da política cultural. Assim, a cidade criativa "é capaz de transformar continuamente sua estrutura socioeconômica, com base na criatividade de seus habitantes e em uma aliança entre suas singularidades culturais e suas vocações econômicas" (REIS, 2009, p.3). De fato, o queijo do Serro (MG), com IG (IP) concedida em 2011, enquanto herança transmitida de pai para filho salvou a região do declínio econômico da exploração do ciclo do ouro, articulando-se à intensificação agropecuária da região (GIESBRECHT et al., 2014a).

Ainda no caso das IGs, na confluência do debate sobre as cidades criativas, ocorre uma ampliação do olhar para a concepção de 'região criativa' que une por laços de tradição, produção em rede e fortalecimento coletivo o artesanato criativo das comunidades. Verifica-se a enorme potencialidade de novos produtos na extensa geografia brasileira passíveis de solicitação e obtenção da certificação a exemplo dos doces da cidade de São Cristóvão - SE (queijadas, bricelets e compotas), das cabacinhas de resina de Japaratuba - SE, do licor de mangaba produzido em vários municípios sergipanos, o açaí de sabor terroso e forte de Belém - PA, consumido com peixe frito no Mercado Ver-o-Peso, dentre tantas outras possibilidades. As opalas preciosas e joias artesanais de Pedro II (PI), embora sejam ressaltadas suas características geológicas (mineração) uma vez que o município possui a única reserva de gemas nobres de opala do país e é a segunda maior do mundo (GUIMARÃES, 2017), diferente de produtos outros minerais, é também valorizada pelo trabalho artesanal de lapidação e transformação das gemas em artesanato, pensado como importante elemento cultural da região piauiense. Sua IG (IP) foi obtida em 2012.

O catálogo Velho Chico Sergipano. Indicação Geográfica produzido por Soares (2018) relacionou produtos associados ao turismo com potencial de IG na rota do sertão, cujo acesso pela SE 203, margeada muitas vezes pelo rio São Francisco, perpassa diversos municípios. Espaços estes com produtos típicos marcados pela cultura histórica e tradição regional como o queijo coalho, a renda de bilro e o mel do sertão sergipano. Já no Baixo São Francisco destacam-se o doce de batata de Propriá, o pólen de Brejo Grande, a cerâmica de Santana de São Francisco.

É nesse panorama de reconhecimento das tradições regionais e instrumentalização dos produtores para a sustentabilidade econômica, ambiental e salvaguarda cultural através das IGs que a Educação não-formal surge como uma possibilidade de 'fora do ambiente' escolar instruir uma consciência coletiva que apoie o empoderamento dos agentes sociais presentes nas comunidades artesãs ou agropecuárias. Uma Educação que promova a apropriação dos saberes para uso social. 
Cada vez mais os organismos internacionais do campo educativo preconizam que os indivíduos devem estar continuamente aprendendo, que a escola formal apenas não basta, que se deve aprender a aprender. Os conteúdos rígidos dos currículos são questionados, novos saberes são descobertos identificados/identificados fora das instituições escolares, fundamentais para o crescimento/desenvolvimento dos indivíduos enquanto seres humanos, assim como para o desempenho destes indivíduos no processo de trabalho em face às novas exigências do mundo globalizado (GOHN, 2014, p.38).

Mas para que essa atividade que alia criatividade, cultura, produção econômica comunitária e saberes democráticos seja bem sucedida há que se buscar a saída das paredes das escolas, o adentrar nas casas das associações, nos galpões das cooperativas, nas quadras de esporte dos povoados, munidos de ideias pedagógicas que tornem inteligíveis as regras do INPI, os benefícios e problemáticas da certificação, o estímulo à cobrança das autoridades públicas enquanto instância de governância civil para o apoio, divulgação e debate coletivo do desenvolvimento daquele grupo social.

\section{EDUCAÇÃO NÃO-FORMAL EM COMUNIDADES CRIATIVAS: OFICINAS COLABORATIVAS.}

A abordagem dada à Educação não-formal junto às comunidades urbanas ou campesinas, visando a melhoria de sua qualidade de vida no acesso ao conhecimento criativo e sustentabilidade econômica colaborativa, tem sido desenvolvida a partir de projetos sociais educativos tendo o associativismo como cenário de realização e consolidação da autonomia, empatia, iniciativa e resolução de problemas cotidianos coletivos (GOHN, 2009, p.29-30).

Por isso, é perceptível uma distinção entre o espaço escolar e o espaço da cidade no que diz respeito à concepção de ensino-aprendizagem que se pretende adotar, pois

[...] o espaço da escola é marcado pela formalidade, pela regularidade, pela sequencialidade. $\mathrm{O}$ espaço da cidade (apenas para definir um cenário da educação não-formal) é marcado pela descontinuidade, pela eventualidade, pela informalidade. A educação não-formal é também uma atividade educacional organizada e sistemática, mas levada a efeito fora do sistema formal (GADOTTI, 2005, p. 2).

Ou seja, a seriedade e comprometimento, bem como a organização e o planejamento que visa alcançar bons resultados na ampliação dos direitos, na apropriação valorativa da cultura e da cidadania dos envolvidos são princípios essenciais nos projetos de Educação não-formal. Conforme Gohn, o direcionamento dessas ações nas comunidades volta-se para

a capacitação dos indivíduos para o trabalho, por meio da aprendizagem de habilidades e/ou desenvolvimento de potencialidades; a aprendizagem e exercício de práticas que capacitam os indivíduos a se organizarem com objetivos comunitários, voltadas para a solução de problemas coletivos cotidianos. (GOHN, 2009, p.31)

A realização de oficinas de Educação não-formal para instrumentalização das IGs como processo de desenvolvimento da Economia Criativa local, em seu planejamento, 
divide-se em três etapas: 1) Pesquisa, teoria e método para ministrantes; 2) Sensibilização da comunidade e oficinas; 3) Validação dos resultados, elaboração de documentação e demanda da gestão pública.

\section{PRIMEIRA ETAPA: PESQUISA DE DADOS E FUNDAMENTAÇÃO TEÓRICA, METODOLÓGICA DOS MINISTRANTES}

Os estudos de viabilidade socioeconômica vêm à tona como procedimentos iniciais para a coleta de dados, compreensão da realidade local e planejamento de atividades que considerem não apenas a rentabilidade à médio e longo prazo, mas também a infraestrutura, as tradições e as decisões técnicas, abrangendo legislação, tecnologias, níveis de urbanização, financiamento, segmentos econômicos locais, empregabilidade, impacto ambiental, dentre outros (GIRARDI et al., 2015).

A proposição de um estudo de viabilidade socioeconômica e cultural preliminar em povoados com produtos atrativos para a obtenção de IGs pressupõe a própria formação de docentes e discentes universitários, enquanto ministrantes das oficinas, antes de irem para campo. Os conhecimentos deverão ser elaborados em oficinas multidisciplinares (formação em Geografia, Sociologia, História, Arquitetura e Urbanismo, Antropologia, Direito, etc.) com pesquisadores experientes nessa prática para que a execução das ideias esteja tenha por base a realidade local concreta e não uma idealização.

Os dados da área geográfica na qual se pretende trabalhar podem ser coletados on line (IBGE, 2019) para levantar a área territorial, o quantitativo demográfico, especificado em distinção de gênero e estimativa de alfabetização e nivelamento escolar. Igualmente o Censo Educacional de 2015, realizado pelo Instituto Nacional de Estudos e Pesquisas Educacionais (INEP, 2015) oferece uma importante base de informações relacionadas ao quantitativo de escolas, alunos matriculados e número de professores.

O Índice de Desenvolvimento Humano Municipal (IDHM) confere acesso aos dados econômicos comparativos sobre as despesas e receitas orçamentárias dos municípios, mapeando as áreas, a partir de três importantes dimensões: a oportunidade de viver uma vida longa e saudável, de acesso ao conhecimento e ter um padrão de vida que garanta as necessidades básicas, representadas pela saúde, educação e renda (PNUD, 2010). Já o Sistema de Informações Contábeis e Fiscais (SICONFI) do Tesouro Nacional permite acessar gráficos informativos e comparativos com receitas orçamentárias e despesas dos municípios, assim como o Índice FIRJAN de Desenvolvimento Municipal (IFDM) é importante para a percepção dos índices de desenvolvimento comparativos com as áreas de Educação, Saúde, Emprego e Renda.

Deve-se ainda realizar uma caracterização histórica e cultural da área de atuação. Para isso, além do levantamento bibliográfico, os arquivos públicos (hemerotécas, manuscritos, coleções iconográficas, relatórios) e as superintendências do Instituto do Patrimônio Histórico e Artístico Nacional (IPHAN) podem subsidiar com profundidade esse percurso de 'encontro do outro'. 
Adicionalmente uma consulta a base de dados do INPI (registros de IG concedidos e submetidos), bem como junto ao SEBRAE e às secretarias municipais e/ou estaduais evitará a perda de tempo em planejar uma ação para uma determinada área que já esteja com sua solicitação em curso.

De posse de tais informações, pode-se montar grupos multidisciplinares para definir as atividades junto às comunidades em foco.

\section{SEGUNDA ETAPA: SENSIBILIZAÇÃO DA COMUNIDADE E CONDUÇÃO DAS OFICINAS}

A escolha da comunidade dependerá do potencial de seu produto (atendimento aos critérios do INPI, Fig. 4) além de sua disposição em participar dessa iniciativa. Por isso, a sensibilização não apenas dos líderes das associações, mas de todos os seus membros para que participem das reuniões e sejam ouvidos por pesquisadores e representantes da gestão pública será essencial. É necessário que se deixe claro que será constituído um espaço dialógico, de trocas e não um monólogo hierarquizado, externo à realidade da comunidade.

Após os contatos iniciais com a comunidade e sua aprovação das atividades propostas, as oficinas deverão ser realizadas com no máximo uma hora de duração (totalizando no máximo seis encontros, duas vezes ao mês).

Figura 4: Critérios do INPI para Concessão de IGs

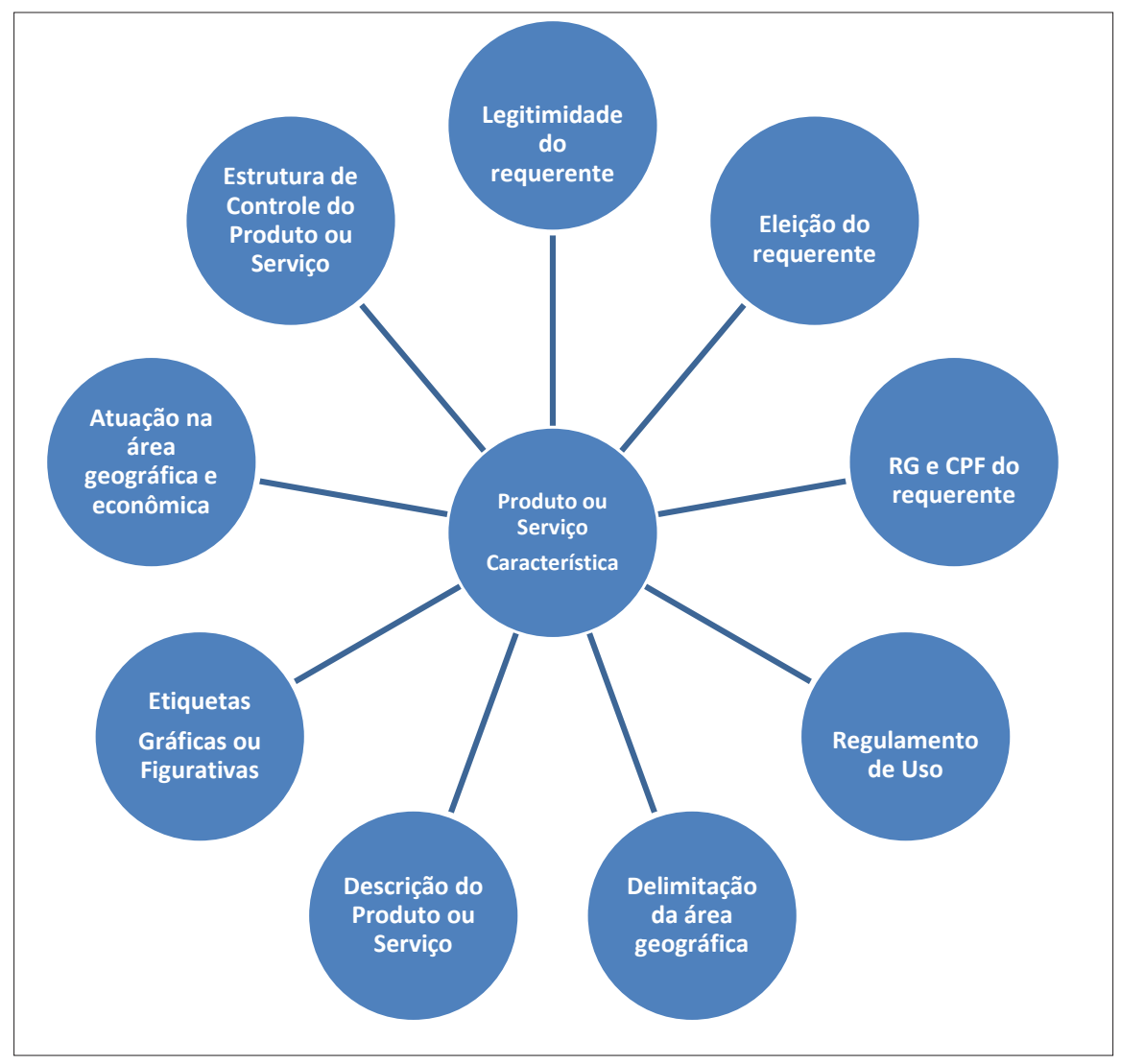

Fonte: modif. de INPI, 2019. 
No primeiro encontro, a definição de IG e suas modalidades, seus benefícios e restrições para a economia local e os critérios para solicitação de registro no INPI devem ser apresentados à comunidade de modo visual através de um diagrama com a síntese das ideias básicas. E a partir destes, a divisão em pequenos grupos de trabalho se voltará para o trabalho com a "Tríade das Possibilidades" (Fig. 5).

Figura 5: Tríade das Possibilidades

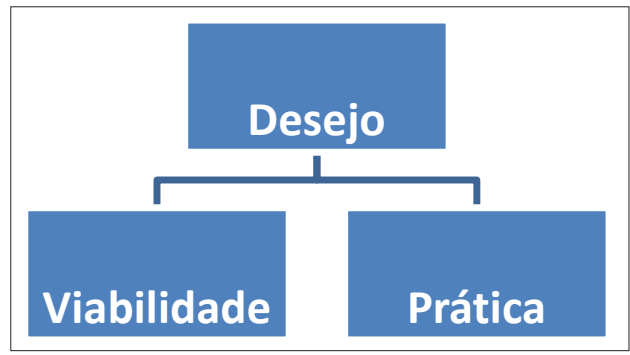

Fonte: a autora.

Esse recurso visual tem como objetivo fazer com que os grupos pensem sobre os desejos que possuem para a melhoria da vida na comunidade, verificando os produtos e/ ou serviços transmitidos de geração para geração com valor simbólico-cultural e monetário, o contexto de sua produção (linha do tempo, identificando continuidades, mudanças e grupos produtores). As ideias são organizadas em cartazes com a escrita ou fixação de post-its nos retângulos. Essa atividade converge para estimular a percepção, a análise, a comparação e a dedução no processo de observação de sua própria realidade.

A comunidade precisa sentir-se integrada em um sistema de valorização de suas propostas, desejos, vivências e dúvidas. Deve-se levar em consideração que os pesquisadores/representantes da gestão pública serão sempre vistos como agentes externos à comunidade - aqueles que não residem ali, não experimentam seu cotidiano em termos de empregabilidade ou ausência dela - e por isso só possuem conhecimento técnico e não de vivência coletiva daquela realidade.

Oferecer uma instrumentalização técnica do processo de IGs é apenas um objetivo secundário, uma vez que o princípio norteador será sempre o empoderamento daqueles grupos para que sejam eles próprios os gestores de suas ações nas escolhas do viés econômico ligado à sua criatividade produtiva. Isso posto, segue a intenção de que

[...] não existem conteúdos "chapados", absorvidos acriticamente, de fora para dentro. Sempre há recriação, reelaboração interna, mental, de tal forma que o que foi aprendido é retraduzido por novos códigos, de dentro para fora, e ao se expressar como linguagem ou comportamento, é um conhecimento elaborado (GOHN, 2014, p.39).

No segundo encontro, a sistematização das ideias refletidas e expostas coletivamente, enquanto formas de aprendizagem coletivas, pode gerar uma 'nuvem de palavras' (Fig. 6), nas quais os envolvidos retomam suas considerações anteriores de modo resumido através de algumas palavras, sendo cada item debatido, buscando identificar os problemas locais para tentar equacionar, de modo conjunto, soluções e proposições adequadas à cada contexto. 


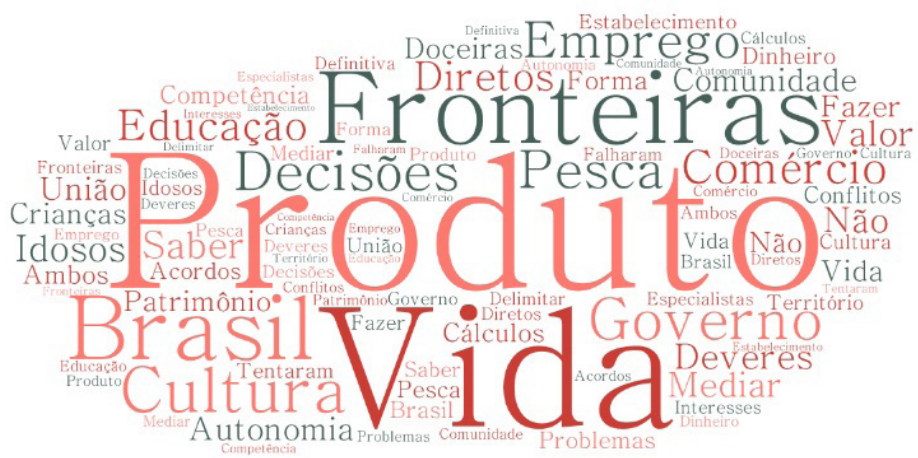

Fonte: a autora, a partir de https://wordart.com/create, 2019.

Em um terceiro encontro a criação de uma Mandala (Fig. 7) mostra-se uma ferramenta visual capaz de organizar as informações coletivas para a simplificação do processo de elaboração do relatório circunstanciado. Para os moradores de povoados interioranos o preparo do relatório circunstanciado revela-se uma incógnita, pois envolve uma minuciosa coleta de dados desde os documentos da própria associação ou cooperativa (atas de criação, atas de reunião, regulamento de funcionamento, comprovantes de participação em feiras para exposição e comercialização dos produtos) até matérias jornalísticas, trabalhos acadêmicos, atividades culturais relacionadas ao produto e outros.

Figura 7: Mandala de IG

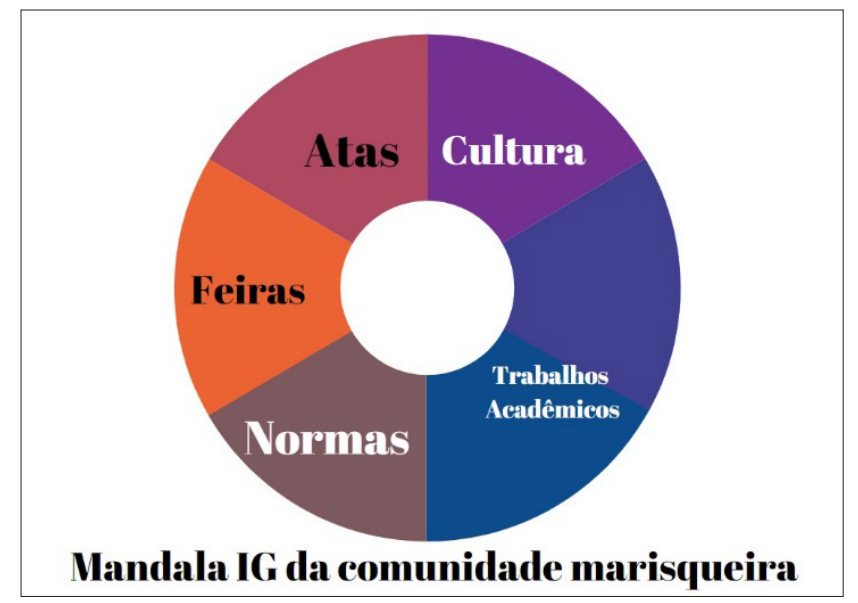

Fonte: a autora, a partir de https:/ / www.canva.com/design, 2019.

\section{TERCEIRA ETAPA: VALIDAÇÃO DOS RESULTADOS, ELABORAÇÃO DE DOCUMENTAÇÃO E DEMANDA DA GESTÃO PÚBLICA}

Quando se trata de um produto cujo valor de patrimônio cultural já foi agregado pela realização da metodologia do Inventário Nacional de Referências Culturais (INRC) pelo corpo técnico do IPHAN e membros da comunidade, obtendo o registro como 
patrimônio imaterial no livro dos saberes, há um dossiê específico que comporta muitas das informações requisitadas pelo INPI e que por isso poderá ser anexado ao processo de solicitação da IG, facilitando a pesquisa.

O desenvolvimento do Inventário Nacional de Referências Culturais - INRC significa a disponibilização de um instrumento essencial para a identificação e documentação de bens culturais e, consequentemente, para as possibilidades de preservação desses bens. Vale enfatizar que o INRC é um instrumento de identificação de bens culturais tanto imateriais quanto materiais (IPHAN/MINC, 2000, p.8).

O preenchimento de formulários de solicitação também evocará algumas dúvidas e o acompanhamento de técnicos do SEBRAE e do INPI (que podem ser convidados e financiados por prefeituras e governos estaduais em sua viagem) resultará no esclarecimento de dúvidas e dificuldades. Tal procedimento poderá ser feito em um quarto encontro.

A realização de um quinto encontro com procedimentos teste, onde há o preenchimento coletivo de cópias do formulário para que cada um, ao seu tempo e maturação de ideias, entenda sua execução propicia a aprendizagem ativa pelo 'fazer'.

Os ministrantes e organizadores das oficinas na ambiência das comunidades, ao trabalharem na perspectiva da Educação não-formal, devem estar também cientes de que

A educação não formal é aquela que se aprende "no mundo da vida", via os processos de compartilhamento de experiências, principalmente em espaços e ações coletivos cotidianas. Nossa concepção de educação não formal articula-se ao campo da educação cidadã - a qual no contexto escolar pressupõe a democratização da gestão e do acesso à escola, assim como a democratização do conhecimento. Na educação não formal, essa educação volta-se para a formação de cidadãos (as) livres, emancipados, portadores de um leque diversificado de direitos, assim como de deveres para com o(s) outro(s) (GOHN, 2014, p.40).

Por isso, trazer exemplos concretos como produtos já certificados (Fig. 8) para que os participantes visualizem, toquem, provem e emitam suas opiniões, mostrar seu desempenho econômico antes e depois da certificação da IG, suas vantagens e dificuldades, uma cópia do relatório apresentado por um ou mais desses produtos, configura essa troca de conhecimentos de forma sensorial, subjetiva, mas também assertiva no que tange à um exemplo real.

Figura 8: Selos de IG brasileiras (ES, MG e AL)
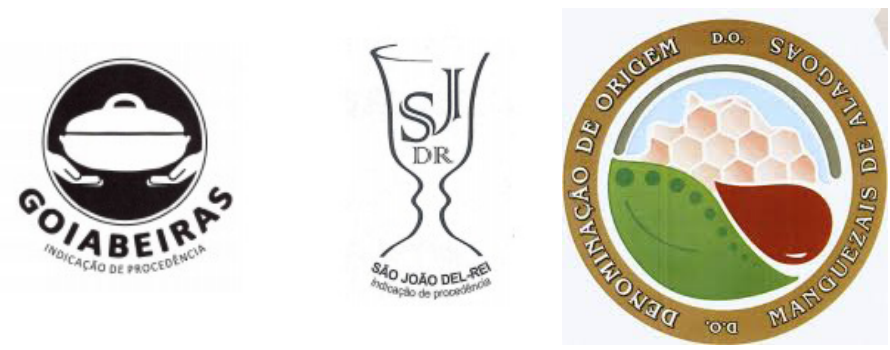

Fonte: INPI, 2019. 
O estímulo à formação de redes solidárias é essencial para o sucesso do empreendimento, uma vez que o pedido de uma IG que envolva uma região produtora com mais de um município, associação ou cooperativa fortalece os elos da cadeia produtiva. Foi assim na região do Jalapão (Tocantins) do artesanato em capim dourado, na região das panelas de Goiabeiras (ES), no Vale dos Vinhedos (RS), dentre outros. Um esquecimento, nesse processo, foi identificado na IG da renda irlandesa (SE) atribuída somente ao município de Divina Pastora, quando outras localidades como Laranjeiras e Riachuelo também a produzem.

A colaboração favorece a democratização de oportunidades e benefícios visando a apropriação comunitária desses bens no desenvolvimento de sua atividade econômica. A competitividade que se alia à coletividade promove articulações mais sólidas frente aos desafios e oscilações do mercado nos momentos da negociação do produto.

Um sexto encontro que traga dados sobre a legislação, direitos e deveres, impostos, marketing do produto, responsabilidades ambientais, acesso ao mercado (vendas locais, nacionais e exportação), alianças com outros setores econômicos como o do turismo, além da inclusão digital no manuseio de ferramentas computacionais, será muito importante para lidar com as expectativas geradas quanto aos custos e remuneração da produção.

Os oficineiros devem planejar suas atividades dentro do cronograma pré-estabelecido com a comunidade, introduzindo o assunto, debatendo-o, esperando sua maturação, encaminhando as proposições coletivas para soluções viáveis no cotidiano da comunidade, avaliando regularmente a participação dos agentes sociais e sua própria atuação na mediação pedagógica.

\section{À GUISA DE CONCLUSÃO}

A proposta de oficinas de Educação não-formal para a instrumentalização da técnica dos procedimentos para a solicitação e obtenção do registro de IG é parte de uma compreensão bem maior que abrange a promoção da cidadania, da democracia, da formação de redes de solidariedade e integração da criatividade em uma atividade de autogestão econômica capaz de viabilizar a sustentabilidade da comunidade.

É necessário sair dos muros universitários e socializar o conhecimento acadêmico numa ambiência de troca, na qual a universidade cumpre seu papel social e aprende a desenvolver uma comunicação inteligível e valorativa com seu entorno. No encontro com a comunidade extramuros, através de uma vivência de diálogo horizontal, se realiza o papel da instituição de ensino superior como parceira em suas demandas socioeconômicas e culturais.

Existirão conflitos, frustrações, recuos e recomeços que fazem parte da vida humana em sociedade. Mas somente assim, ambos - comunidades, universidades/representantes da gestão pública - poderão construir um canal para tomada de decisões mais equilibradas, lidando com os problemas reais da população, suas dúvidas e esperanças.

Oficinas de Indicação Geográfica em comunidades criativas geram modos de lidar tanto com as expectativas positivas quanto com as negativas, formando o cidadão para a 
busca de alternativas, a solução de problemas e a externalização de ideias com potencial de sucesso vinculadas ao seu manuseio das coisas que o cercam no mundo.

\section{REFERÊNCIAS}

ARTESOL. Paneleiras de Goiabeiras. Disponível em: http://www.artesol.org.br/rede/membro/ paneleiras_de_goiabeiras. Acesso em: 25 jul. 2019.

ASHTON, Mary Sandra Guerra. Cidades criativas: produção e consumo turístico. In: NETTO, Alexandre Panosso; ANSARAH, Marília Gomes dos Reis (Ed.) Produtos turísticos e novos segmentos de mercado. Planejamento, criação e comercialização. Barueri: Manole, 2015.

CARVALHO, Gisele. A castanha de caju: Fonte de economia e produção em Picos. Disponível em: http:// www.faculdadersa.com.br/vemverosemiarido/index.php/2015/12/01/a-castanha-de-caju-fonte-deeconomia-e-producao-em-picos-2/. Acesso em: 20 fev. 2017.

FIRJAN - Federação das Industrias do Rio de Janeiro. IFDM. Disponível em: https:/ / www.firjan.com.br/ ifdm/. Acesso em: 10 ago. 2019.

FLORIDA, R. The Rise of the Creative Class and how It's Transforming Work, Leisure, Community and Everyday Life. New York: Basic Books, 2002.

GADOTTI, Moacir. A Questão da Educação Formal/Não-Formal. In: INSTITUT INTERNATIONAL DES DROITS DE L'ENFANT (IDE). Droit à l'éducation: solution à tous les problèmes ou problème sans solution? Sion (Suisse), 2005.

GIESBRECHT, Hulda Oliveira; MINAS, Raquel Beatriz Almeida de; GONÇALVES, Marcos Fabrício Welge et al. Indicações geográficas brasileiras. Brasília: SEBRAE, INPI, 2014a.

et al. Indicações geográficas brasileiras - Artesanato. Brasília: SEBRAE, INPI, 2014b.

GIRARDI, Benur A.; OLIVA, Angela M.; ANDRADE, Antonio R. de. Considerações sobre a viabilidade socioeconômica de Centros Culturais e de Criatividade: um Estudo de Caso. In:SIMPOSIODE EXCELENCIA EM GESTAO E TECNOLOGIA, 12, 2015, Rio de Janeiro. Disponível em: https://www.aedb.br/seget/ arquivos/artigos15/30222519.pdf, acesso em: 10 ago. 2019.

GOHN, Maria da Glória. Educação não-formal, educador(a) social e projetos sociais de inclusão social. Meta: Avaliação, Rio de Janeiro, v. 1, n. 1, p. 28-43, jan./ abr. 2009. Disponível em: http:/ / revistas.cesgranrio. org.br/index.php/metaavaliacao/article/viewFile/1/5. Acesso em: 10 ago. 2019.

Educação Não Formal, Aprendizagens e Saberes em Processos Participativos. Investigar em Educação - II a Série, n.1, p.35-50, 2014. Disponível em: <http:/ / pages.ie.uminho.pt/inved/index.php/ie/ article/view/4/4>, Acesso em: 20 mar. 2017.

GUIMARÃES, Hanny. Opala: preciosidade do Sertão ganha o mundo Disponível em: http:// revistagloborural.globo.com/Revista/Common/0,EMI211452-18071,00-OPALA+PRECIOSIDADE+DO+ SERTAO+GANHA+O+MUNDO.html. Acesso em: 15 mar.2017.

HORTA, Maria de Lourdes Parreiras. Educação Patrimonial. PGM 5 - A multiplicação do Método. 2019. Disponível em: http:/ / portal.iphan.gov.br/uploads/temp/educacao_patrimonial.pdf. Acesso em: 10 ago. 2019.

IBGE - Instituto Brasileiro de Geografia e Estatística. Cidades. Disponível em: https://cidades.ibge.gov. br/. Acesso em: 10 ago. 2019.

INEP. Censo Escolar 2015. Disponível em: http://inep.gov.br/censo-escolar. Acesso em: 10 ago. 2019.

INPI - Instituto Nacional de Propriedade Industrial. Guia do Usuário. Módulo de Indicação Geográfica e Peticionamento Eletrônico. Disponível em: http://www.inpi.gov.br/menu-servicos/indicacaogeografica/guia-basico-de-indicacao-geografica. Acesso em: 20 jul. 2019. 
L Lista de Indicações Geográficas Reconhecidas. Disponível em: http://www.inpi. gov.br/menuservicos/indicacaogeografica/arquivos/lista_com_as_indicacoes_geograficas_ concedidas_-_10-03-2015.pdf. Acesso em: 10 ago. 2019.

Site (histórico). Disponível em: http:/ / www.inpi.gov.br/sobre/estrutura. Acesso em: 02 set. 2016.

IPHAN/MINC - Instituto do Patrimônio Histórico e Artístico Nacional. Departamento de Identificação e Documentação. Inventário nacional de referências culturais: manual de aplicação. Brasília, 2000.

MAIORKI, Giovane José; DALLABRIDA, Valdir Roque. Interações, Campo Grande, v. 16, n. 1, p. 13-25, jan./jun. 2015.

MARTINS, Josiel. Comercialização da Cajuína para o Brasil cresceu 40\% nos últimos anos. Disponível em: http://www.portalodia.com/noticias/economia/comercializacao-da-cajuina-para-o-brasil-cresceu40-nos-ultimos-anos-138893.html. Acesso em: 20 fev. 2017.

OLIVEIRA, Daniela. Artesanato em capim dourado reflete a atuação da mulher quilombola na cultura do Tocantins. 2016. Disponível em: https://secom.to.gov.br/noticias/artesanato-em-capim-dourado-refletea-atuacao-da-mulher-quilombola-na-cultura-do-tocantins-270047/. Acesso em: 31 jul. 2019.

PIMENTEL, L.O. Curso de propriedade intelectrual \& inovação no agronegócio: Modulo II, indicação geográfica. Florianópolis: MAPA/ FUNJAB, 2014.

PNUD. IDHM - índice de desenvolvimento humano municipal. 2010. Disponível em: http://www. br.undp.org/content/brazil/pt/home/idh0/conceitos/o-que-e-o-idhm.html, Acesso em: 10 ago. 2019.

PORTAL AZ. Cajuína ganha cada vez mais espaço no mercado. Disponível em: https:/ /www.portalaz. com.br/noticia/geral/323227/cajuina-ganha-cada-vez-mais-espaco-no-mercado. Acesso em: 20 de fev. 2017.

REIS, Ana Carla Fonseca. Cidades criativas, turismo cultural e regeneração urbana. 2009. Disponível em: www.gestaocultural.org.br/pdf/Ana-Carla-Fonseca-Cidades-Criativas.pdf, Acesso em: 12 mar. 2013.

; KAGEYAMA, Peter (Orgs.) Cidades criativas: perspectivas. São Paulo: Garimpo de soluções, 2011.

SEBRAE; INPI. Indicação Geográfica. Sinais distintivos coletivos. Proteja sua região. Disponível em: http://www.bibliotecas.sebrae.com.br/chronus/ARQUIVOS_CHRONUS/bds/bds.nsf/b74012230b8bc7 857e72bafed82a4388/\$File/5615.pdf. Acesso em: 20 jan. 2017.

SICONFI - Tesouro Nacional. Disponível em: https:/ / siconfi.tesouro.gov.br/siconfi/index.jsf. Acesso em: 10 ago. 2019.

SOARES, Roberta Nascimento Gonçalves. Velho Chico Sergipano. Indicação Geográfica. Aracaju: IFS, 2018.

SOUSA Libni Milhomem et al. Panorama das Indicações Geográficas vigentes no Brasil. Revista INGI, v.3, n.3, p.378-389, 2019.

ZANANDREA, Gabriela et al. Produtos Tradicionais Portugueses: Indicação Geográfica. Proceeding of ISTI, v. 8, n.1, p.542-548, 2017. Disponível em: http://www.api.org.br/conferences/index.php/ISTI2017/ ISTI2017/paper/viewFile/275/192, Acesso em: 20 jul. 2019.

Data da submissão: 19/ fev./ 2018

Data de aceite: 28/ ago./ 2019 